\title{
QUANTIFYING EARLY INDICATORS OF GLOBAL CLIMATE CHANGE
}

\author{
DIANE DEBINSKI ECOLOGY, EVOLUTION \& ORGANISMAL BIOLOGY \\ IOWA STATE UNIVERSITY $\downarrow$ AMES
}

\section{$\downarrow$ RESEARCH SUMMARY}

One of the more significant voids remaining in our scientific understanding of global climate change is the relationship between climate change and the resulting changes expected in ecological communities. Because a large proportion of the North American landscape has been modified by human activities, it is difficult to assess whether ecological changes are being caused by human activities or climate change. Thus, we must look to landscapes where the modification has been less severe. One of the most pristine landscapes in North America where scientists can study natural processes is that of the Greater Yellowstone Ecosystem. Within this system some of the more sensitive habitats are the montane meadows. These habitats exist along a continuum from very dry (xeric) sagebrush meadows, to flowering (mesic) meadows, to wet (hydric) sedge meadows. Because of the relatively short growing season, species in these meadows can exhibit quick changes in distribution and abundance relative to climatic changes. My research uses satellite images and field surveys to evaluate how meadow habitats and their associated species respond to interannual changes in precipitation and soil moisture. I am examining the plant and butterfly communities to measure the response. Over 100 species of butterflies occur in this area and many are closely associated with specific types of meadows. This research is significant because it will provide an early warning system for assessing the effects of climate change. Documenting changes in montane meadows will assist in understanding how climate change may affect more highly managed areas of the globe.
The research sites include 55 relatively low elevation (2000-2500m) montane meadows arrayed along a hydrological gradient (M1-M6). We focused our work on low elevation meadows $(2000-2500 \mathrm{~m})$, to maximize replication by meadow type and to avoid introducing another environmental gradient (elevation) into our analysis. M1 meadows are hydric with willow (Salix spp.) thickets. M2 meadows are sedge (Carex spp.) marshes. M3 - M4 meadows are mesic and characterized by a forb-grass coverage. M5 meadows have a mixture of sagebrush (Artemisia tridentata) and herbaceous vegetation. M6 meadows are the most xeric in our hydrological gradient, and sagebrush and bare ground are dominant components of cover. We established 55 core sampling sites (minimum of 1 ha in size and the selected sites were as flat as possible to avoid introducing the influence of slope or aspect as a variable); 30 sites were located in the Gallatin region (Gallatin National Forest and the northwest section of Yellowstone National Park - 5 of each of 6 meadow types), and 25 sites were located in the Teton region (Grand Teton National Park and Bridger Teton National Forest - 5 of each meadow type except for M4 meadows, which are not found there). Sites were located a minimum of $500 \mathrm{~m}$ apart. These "core sites" were sampled annually for plants, butterflies, and birds from 1997-2001. During 2002-2005, we sampled only the bird and butterfly communities in the 25 Teton sites due to limited funding. NSF LTREB funding supported field research focused on the plant and butterfly community during 2006 . Below is a summary of the research goals and objectives and some of the preliminary results. 


\section{PROJECT GOAL}

My goal is to determine how interannual variability in precipitation and soil moisture affects montane meadow communities of plants and butterflies. The central hypothesis for the research is that meadow type and species distribution patterns are particularly sensitive to climate variations (e.g., precipitation, soil moisture) at a local level. Thus, the combination of changes in remotely sensed imagery, soil moisture and species composition may provide us with short-term indications (at the level of 1-3 years) of how climatic variation is manifested in this extreme environment. These short-term indicators can then be used to track longer-term changes. I have formulated this hypothesis based upon preliminary findings suggesting that montane meadows exhibit variations in remotely sensed classification as a response to interannual variability of climate. The rationale for the proposed research is that I will be able to determine whether climate variability is affecting ecological communities. I am testing this central hypothesis via the following objectives and associated working hypotheses:

Objective 1: Conduct a pilot test to assess the soil moisture in a subset of each of the meadow types along the hydrological gradient. Variation in soil moisture is the mechanism that I hypothesize is driving changes in this landscape. During 2006, field-based soil moisture probes were tested for assessing differences in soil moisture across the meadow gradient. Working hypothesis 1: Interannual variations in precipitation are capable of causing significant changes in local soil moisture.

Objective 2: Identify plant species that show sensitivity to climate variability as manifested as changes in their distribution and abundance. I am using data from 1997-2006 to examine how interannual climate variability affects plant communities. Working hypothesis 2: Plant species will show interannual shifts in percent cover that are correlated with changes in soil moisture. Because the plant community within each of the meadow types contains a mixture of species with different tolerances for moisture, there is potential for short-term change in perennial plant communities based on the vigor of each of the species. Annual species existing in the seed bank will also have the potential to either flourish or become desiccated depending upon their moisture tolerances and the underlying soil moisture.

Objective 3: Identify butterfly species that show sensitivity to climate variability as manifested as changes in their distribution and abundance. The changes in the plant community will be reflected in the butterfly community based upon species-specific changes in habitat utilization. Because butterflies move freely throughout the landscape, they can focus on important sites for nectar or host plants. As changes occur in the plant community, butterflies will move within the landscape mosaic among meadow types. Working hypothesis 3: Butterfly species will show interannual shifts in distribution and abundance along the hydrological gradient that are correlated with changes in soil moisture. For example, xeric species may move into more mesic sites in a drier year.

\section{$\downarrow$ METHODS}

Regional Weather Data: We will quantify broad-scale changes in precipitation and temperature over time using two national climate weather stations (240775: Big Sky and 486440: Moran 5WNW) to represent the two GYE study regions.

Soil Moisture assessment: Soil moisture meters were installed at one meadow of each type within each sampling region (for a total of 11 sites) in 2006. These meters were monitored and soil samples were taken from each site to calibrate the meters, but there were several problems with animals digging up and disturbing the meters.

Vegetation and Nectar Surveys: Vegetation was surveyed once per season in the middle of the growing season (July) using the 20x20m long-term survey plots. Cover estimates were made to $1 \%$ resolution for the 10 most predominant forb species and woody plant by genus. Grasses, rushes, and sedges (graminoids) were surveyed as a group. Plants will be analyzed for changes in percent cover within 
each of the following functional groups: shallow-rooted forbs, deep-rooted forbs, graminoids, and shrubs. Nectar resources will be quantified by counting the number of racemes for all nectar species along a $1 \mathrm{~m}$ wide transect positioned diagonally across the $50 \times 50 \mathrm{~m}$ butterfly survey plot on the day of the butterfly survey.

Butterfly Species Characterization in Sample Sites: Abundance data were collected annually for butterflies in each of the sampling sites from June to early-August. Butterflies were surveyed twice/season at each of these sites and sampling was temporally spaced to cover the two major emergence periods within the summer. Surveys occurred between 0930-1630 hrs with two people netting for 20 minutes in $50 \times 50 \mathrm{~m}$ plots at each sampling site. Surveys were limited to times when temperature was above 70 $\mathrm{F}$, wind was less than $16 \mathrm{~km} / \mathrm{hr}$. Vouchers were pinned where necessary for ID.

\section{$\downarrow$ PRELIMINARY RESULTS}

We have hypothesized that soil moisture is a major environmental driver in the montane meadow system, and we expect that changes in soil moisture will be differentially reflected across the moisture gradient of meadows and their associated plant and insect communities. We expect that with drying trends, forbs and grasses, which use water from higher in the soil horizon, will decrease in cover whereas woody plants will increase. Our data appear to support this hypothesis (Debinski, unpublished data). We are now in the process of analyzing the butterfly abundance trends over 1997-2006 by host plant preferences. We expect that those butterfly species associated with forbs and grasses will be more significantly affected by drought conditions and changes in percent host plant cover than those associated with woody species and may show greater interannual variance in abundance patterns. Thus, we expect asymmetric and potentially compensatory responses across the soil-plant-insect system. Our hierarchical framework will allow us to predict plant and insect species that may be especially sensitive to changes.
Our research thus far has shown that mesic montane meadows have the highest percent cover and diversity of forbs and exhibit the highest levels of variation of remotely sensed imagery both seasonally and interannually (Debinski et al. 2000; 2002). Remotely sensed data are correlated with variations in both soil moisture and vegetative biomass. During the past ten years (which is considered a time of drought) we have identified several important trends in our meadow plant communities. The butterfly community in hydric to mesic meadows showed changes in distributional patterns towards a state indicative of drier meadows (Debinski et al. 2006). Further, two hydric meadow species were missing from the Teton sites in 2004 (i.e., they were not seen in any of the 25 sites): Boloria frigga, and Euphydryas gillettii, a rare wetland habitat associate. Both species had been observed annually in these sites since 1997 and returned in 2005 and 2006. Such changes may be the random variations observed within one year, but they reinforce the importance of long-term data.

\section{$\downarrow$ Literature Cited}

Debinski, D.M., M.E. Jakubauskas and K. Kindscher. 2000. Montane meadows as indicators of environmental change. Environmental Monitoring and Assessment. 64:213-225.

Debinski, D.M., M.E. Jakubauskas, K. Kindscher, E.H. Saveraid and M. Borgognone. 2002. Predicting meadow communities and species occurrences in the Greater Yellowstone Ecosystem. Pp. 499-506 In: Scott, J.M., P.J. Heglund, M. Morrison, M. Raphael, J. Haufler, B. Wall, (ed.) Predicting Species Occurrences: Issues of Scale and Accuracy. Island Press. Covello, CA.

Debinski, D.M., R.E. VanNimwegen and M.E. Jakubauskas. 2006. Quantifying relationships between bird and butterfly community shifts and environmental change. Ecological Applications 16(1):380-39 